\title{
Ultrassonografia como método para avaliação da composição corporal: uma revisão
}

\section{sistemática}

\author{
Ultrasound as a method for evaluation of body composition: a systematic review \\ Ultrasonido como método de evaluación de la composición corporal: una revisión sistemática
}

Recebido: 27/01/2022 | Revisado: 31/01/2022 | Aceito: 03/02/2022 | Publicado: 05/02/2022

Rommel Larcher Rachid Novais

ORCID: https://orcid.org/0000-0002-6433-5454

Universidade Federal de São João Del Rei, Brasil E-mail: rommel@ufsj.edu.br

André Luís de Oliveira Silveira

ORCID: https://orcid.org/0000-0001-8843-1283

Universidade Federal de São João Del Rei, Brasil

E-mail: andre-luis-oliveira@hotmail.com

Ieda Aparecida Diniz

ORCID: https://orcid.org/0000-0002-0032-6401

Universidade Federal de São João Del Rei, Brasil

E-mail: ieda.diniz@yahoo.com.br

Nivea Aparecida de Almeida

ORCID: https://orcid.org/0000-0002-7910-3031

Universidade Federal de São João Del Rei, Brasil

E-mail: nivea.almeida@hotmail.com

Ana Carolina Corrêa Café

ORCID: https://orcid.org/0000-0003-3715-9392

Universidade Federal de São João Del Rei, Brasil

E-mail: anacarolinacorreacafe@gmail.com

Juscelino de Souza Borges Neto

ORCID: https://orcid.org/0000-0002-4551-3278

Universidade Federal de São João Del Rei, Brasil

E-mail: celinoborges1980@gmail.com

Cezenário Gonçalves Campos

ORCID: https://orcid.org/0000-0001-5650-0096

Universidade Federal de São João Del Rei, Brasil

E-mail: cezenario@yahoo.com.br

Márcia Christina Caetano Romano

ORCID: https://orcid.org/0000-0002-1819-4689

Universidade Federal de São João Del Rei, Brasil

E-mail: marciachristinacs@gmail.com

Joel Alves Lamounier

ORCID: https://orcid.org/0000-0002-0581-3217

Universidade Federal de São João Del Rei, Brasil

E-mail: lamounierjoel@gmail.com

\section{Resumo}

Objetivo: avaliar as aplicabilidades clínicas, as técnicas de exame e comparar o US com demais métodos de composição corporal, de forma a elucidar seus potenciais e limitações. Métodos: selecionados estudos que a ecografia tenha sido empregada paralelamente a tomografia computadorizada, ressonância magnética, DEXA, bioimpedância ou antropometria e que incluíssem em sua amostra adultos jovens. A busca dos artigos foi realizada nas bases de dados Pubmed, Science Direct, Web of Science, Scopus e BVS. Resultados: 2120 artigos foram encontrados nas bases de dados e após as etapas de avaliação, 30 artigos fizeram parte da revisão. De maneira geral, a US mostrou boa correlação com os demais métodos de composição corporal. Na avaliação muscular, a avaliação quantitativa com a medida da espessura ou da área muscular apresentou melhores resultados. Autores obtiveram forte correlação com ressonância magnética utilizando medida de 9 grupos musculares $(r=0,96$ e $r=0,91)$ para homens e mulheres respectivamente. A avaliação qualitativa, pela ecogenicidade muscular, obteve correlações mais fracas. Casuística estudando a confiabilidade e a validade da US frente a RNM reporta a confiabilidade moderada, com coeficiente de correlação interclasse variando de 0.42 a 0.44 . Avaliando tecido adiposo subcutâneo, os trabalhos também demonstraram bons resultados, mesmo medindo o tecido adiposo em apenas duas regiões corporais, os resultados foram consistentes com o DEXA $(r=0,947)$ para homens e $(r=0,909)$ para mulheres. Conclusão: a ultrassonografia é um método útil para a 
estimativa do tecido adiposo e do tecido muscular, apresentando boa correlação com métodos de composição corporal mais amplamente utilizados.

Palavras-chave: Composição corporal; Ultrassonografia; Fotodensitometria de raios X; Imageamento por ressonância magnética; Tomografia.

\begin{abstract}
Objective: To evaluate the clinical applicability, examination techniques and compare the US with other body composition methods, to elucidate its potentials and limitations. Methods: Studies were selected in which echography was used in parallel with computed tomography, magnetic resonance, DEXA, bioimpedance, or anthropometry and that included young adults in their sample. The search for articles was performed in Pubmed, Science Direct, Web of Science, Scopus, and BVS databases. Results: 2120 articles were found in the databases and after the evaluation steps, 30 articles were part of the review. In general, the US showed a good correlation with other body composition methods. In muscle assessment, the quantitative assessment with the measurement of muscle thickness or area showed better results. The authors obtained a strong correlation with MRI using measurements of 9 muscle groups $(r=0.96$ and $r=0.91)$ for men and women, respectively. Qualitative assessment, due to muscle echogenicity, had weaker correlations. A sample studying the reliability and validity of US against MRI reports moderate reliability, with an interclass correlation coefficient ranging from 0.42 to 0.44 . Assessing subcutaneous adipose tissue, the studies also showed good results, even measuring adipose tissue in only two body regions, the results were consistent with DEXA ( $\mathrm{r}=0.947)$ for men and $(\mathrm{r}=0.909)$ for women. Conclusion: ultrasound is a useful method for estimating adipose tissue and muscle tissue, showing a good correlation with the most widely used methods of body composition.
\end{abstract}

Keywords: Body composition; Ultrasonography; Absorptiometry photon; Magnetic resonance imaging; Tomography.

\title{
Resumen
}

Objetivo: evaluar la aplicabilidad clínica, las técnicas de exploración y comparar la ecografía con otros métodos de composición corporal, con el fin de dilucidar sus potencialidades y limitaciones. Métodos: se seleccionaron estudios en los que se utilizó ecografía en paralelo con tomografía computarizada, resonancia magnética, DEXA, bioimpedancia o antropometría y que incluyeron a adultos jóvenes en su muestra. La búsqueda de artículos se realizó en las bases de datos Pubmed, Science Direct, Web of Science, Scopus y BVS. Resultados: Se encontraron 2120 artículos en las bases de datos y luego de los pasos de evaluación, 30 artículos fueron parte de la revisión. En general, la ecografia mostró una buena correlación con otros métodos de composición corporal. En la evaluación muscular, la evaluación cuantitativa con medición de grosor o área muscular presentó mejores resultados. Los autores obtuvieron una fuerte correlación con la resonancia magnética utilizando mediciones de 9 grupos de músculos $(r=0,96 \mathrm{r}=0,91)$ para hombres y mujeres, respectivamente. La evaluación cualitativa, debido a la ecogenicidad muscular, tuvo correlaciones más débiles. Una muestra que estudia la confiabilidad y validez de la ecografía en comparación con la resonancia magnética reporta una confiabilidad moderada, con un coeficiente de correlación entre clases que varía de 0.42 a 0.44 . Al evaluar el tejido adiposo subcutáneo, los estudios también mostraron buenos resultados, incluso midiendo el tejido adiposo en solo dos regiones del cuerpo, los resultados fueron consistentes con DEXA $(r=0.947)$ para hombres y $(r=0.909)$ para mujeres. Conclusión: la ecografía es un método útil para estimar tejido adiposo y tejido muscular, presentando una buena correlación con los métodos de composición corporal más utilizados.

Palabras clave: Composición corporal; Ultrasonografía; Absorciometría de fotón; Imagen por resonancia magnética; Tomografía.

\section{Introdução}

Em seres humanos a composição corporal pode ser analisada e avaliada sob variadas perspectivas dependendo do objetivo do estudo ou dos instrumentos usados. É possível o estudo do corpo quanto a sua composição em diferentes níveis: atômico, molecular, celular, tissular-sistêmico e corporal total (Wang et al., 1992). Fatores como a disponibilidade de equipamentos e o contexto clínico também influenciam decisivamente na escolha dos compartimentos corporais analisados. Embora modelos que avaliem quatro ou mais compartimentos corporais sejam possíveis de serem realizados, em muitas situações clínicas, o estudo corporal menos estratificado, como fazendo uso de apenas dois compartimentos, um relativo à "massa de gordura", e o outro de "massa livre de gordura" pode ser o mais adequado para a situação clínica que o exame está inserido (Fosbol et al., 2014).

Com uso da ultrassonografia (US) é possível determinar a composição corporal do compartimento tissular-sistêmico (Bazzocchi et al., 2014), avaliando parâmetros como o tecido muscular (Tillquist et al., 2014; Midorikawa et al., 2015), tecido adiposo (Midorikawa et al., 2011) ou órgãos específicos (Bazzocchi et al., 2014). As principais características positivas para o 
uso da US devem-se ä sua ampla disponibilidade, baixo custo, portabilidade e por tratar-se de método não invaso. Além disso mostra ótima correlação inter e intra-avaliador, e capacidade de uso seriado para avaliação de resposta terapêutica (Ceniccola et al., 2018; Thoirs et al., 2009). A essas qualidades, soma-se o fato de o US ter sido alvo de estudos de validação clínica, que concordaram afirmativamente quanto ao seu potencial (Tillquist et al., 2014; Midorikawa et al., 2015; Midorikawa et al., 2011; Thoirs et al., 2009). Contudo, apesar de sua ampla utilização no diagnóstico de inúmeras doenças e condições clínicas, este método tem sido pouco utilizado na determinação da composição corporal.

Esta revisão sistemática da literatura tem como objetivo avaliar as aplicabilidades clínicas, as técnicas de exame e comparar o US com demais métodos de composição corporal. Os resultados trazem os dados de forma a elucidar seus potenciais e limitações, contribuindo para a maior aproximação desse método de composição corporal da realidade do profissional de saúde.

\section{Metodologia}

Trata-se uma revisão sistemática da literatura realizada com base na diretriz de Itens de Relatório Preferenciais para Revisões Sistemáticas e Meta-análises - A Declaração PRISMA (Page et al, 2021).

A pesquisa busca responder à pergunta: Quais são as aplicações e como é o desempenho da ultrassonografia comparada a outros métodos de avaliação da composição corporal em adultos? A partir da pergunta norteadora construiu-se a estrutura PECO (Pessoas: adultos jovens, Exposição: ultrassonografia. Comparação: DEXA, tomografia computadorizada, ressonância magnética, antropometria e bioimpedância. Resultados/Outcomes: composição corporal).

Considerou-se elegíveis os estudos nos quais o ultrassom foi utilizado em conjunto a pelo menos um outro método de composição corporal mais amplamente difundido ou considerado padrão ouro. Foram selecionados estudos que a ecografia tenha sido empregada paralelamente a tomografia computadorizada, ressonância magnética, DEXA, bioimpedância ou antropometria e que incluíssem em sua amostra adultos jovens (18-24 anos). Não foi utilizado filtro para seleção de data de publicação dos estudos, sendo avaliados artigos de todos os anos disponíveis nos bancos de dados.

Foram excluídos os artigos com modelos animais, estudos que não utilizavam o US como avaliador de composição corporal, estudos com uso de imagens em modo-A ou de aparelhos de US específicos para determinação de massa óssea. Também foram excluídos relatos de caso e revisões de literatura.

A busca dos artigos foi realizada nas bases de dados Pubmed, Science Direct, Web of Science, Scopus e BVS. Como estratégia de busca foram utilizadas as seguintes palavras-chave contidas no Medical Subject Headings (MESH): "Adultos jovens", "Ultrassom", "DEXA", “Tomografia Computadorizada", "Ressonância Magnética", "Antropometria” e "Bioimpedância". Os MeSH e entretermos supracitados foram combinados com os operadores boleanos AND e OR para cada uma das bases informadas. O período de busca e identificação dos artigos ocorreu no mês de janeiro de 2021.

A totalidade dos artigos obtidos em cada base de dados foram importados e reunidos em um Banco de Dados de domínio dos pesquisadores. Posteriormente, todos foram exportados para o software Rayyan, disponível gratuitamente em https://www.rayyan.ai/. Essa ferramenta permite inicialmente a remoção de artigos duplicados dentre as bases de dados. Os remanescentes foram avaliados por dois pesquisadores de forma independente. Inicialmente, foram lidos títulos e resumos dos artigos, de modo a excluir aqueles de discrepância grosseira com o tema escolhido; os demais, tiveram sua metodologia lida para conferir se atendiam aos critérios de inclusão da presente revisão. Esse processo foi feito com blindagem durante todo o período de leitura, de modo que um pesquisador não tinha ciência das escolhas do outro.

Ao término da fase 1 de leitura, a blindagem foi removida e houve cruzamento dos artigos escolhidos por cada pesquisador. Artigos que foram incluídos e excluídos simultaneamente por ambos os pesquisadores (de forma concordante) foram imediatamente destinados para inclusão ou exclusão. Os artigos nos quais houve discordância foram novamente avaliados, de modo a buscar um consenso entre os examinadores; caso isso não fosse obtido, um terceiro pesquisador foi recrutado para 
dissolver a discordância. Os artigos incluídos ao final de todo processo foram submetidos à leitura na íntegra e então separados por grupos conforme o parâmetro da composição corporal o qual avaliavam (tecido adiposo ou massa muscular). Os resultados obtidos e as inferências realizadas são apresentadas nas seções a seguir. Um resumo das etapas de condução da revisão é demonstrado na Figura 01.

Os artigos selecionados para leitura na íntegra foram avaliados e classificados por meio de um escore de qualidade metodológica proposto para esse fim. (Downs et al., 1998). O score Downs e Black visa avaliar os estudos por meio de 27 itens, que analisam a validade interna, validade externa e poder estatístico dos estudos. Trata-se de um instrumento aplicável tanto para estudos com desenho experimental ou observacional. Na avaliação de estudos observacionais são removidos cinco dos vinte e sete itens, pois esses se referem unicamente a estudos com delineamento experimental; os demais são mantidos normalmente.

O processo de avaliação dos manuscritos por esse instrumento foi realizado por dois pesquisadores de forma independente, R.L.R.N. e N.A. Em caso de discordância os conflitos foram resolvidos por um terceiro pesquisador, A.L.O.S. Segundo um estudo brasileiro recente, são considerados metodologicamente adequados aqueles estudos cuja pontuação atingida após o uso do instrumento de Downs foi superior a 70\% da pontuação máxima possível para aquele tipo de estudo, ou seja, 20 e 16 pontos para estudos experimentais e observacionais, respectivamente. (Baldoni et al., 2019).

\section{Resultados e Discussão}

A partir dos MeSH e entretermos aplicados em cada base de dados, foi obtido um montante total de 2120 artigos, a saber: Science Direct - 110; Web of Science - 24; Scopus - 1417; BVS - 76; Pubmed - 493. A totalidade desses trabalhos foram exportados para o aplicativo Rayyan, e as duplicatas dentre diferentes bases de dados (i.e artigos inseridos duas vezes por terem sido obtidos a partir de duas ou mais bases simultaneamente) foram devidamente removidas, restando 2046 artigos. Uma vez terminada a etapa de blindagem, os pesquisadores envolvidos incluíram de forma concordante 30 artigos, que compõem a amostra final de avaliação da presente revisão. A Figura 01 mostra as etapas da seleção dos artigos. A avaliação da qualidade metodológica foi considerada na discussão dos resultados. Um total de 2120 artigos foram selecionados conforme mostrado na Figura 1. Após todas as etapas um total de 30 artigos fizeram parte da revisão, segundo os critérios metodológicos utilizados. 
Research, Society and Development, v. 11, n. 2, e56111226221, 2022

(CC BY 4.0) | ISSN 2525-3409 | DOI: http://dx.doi.org/10.33448/rsd-v11i2.26221

Figura 1: Fluxograma das etapas de seleção.
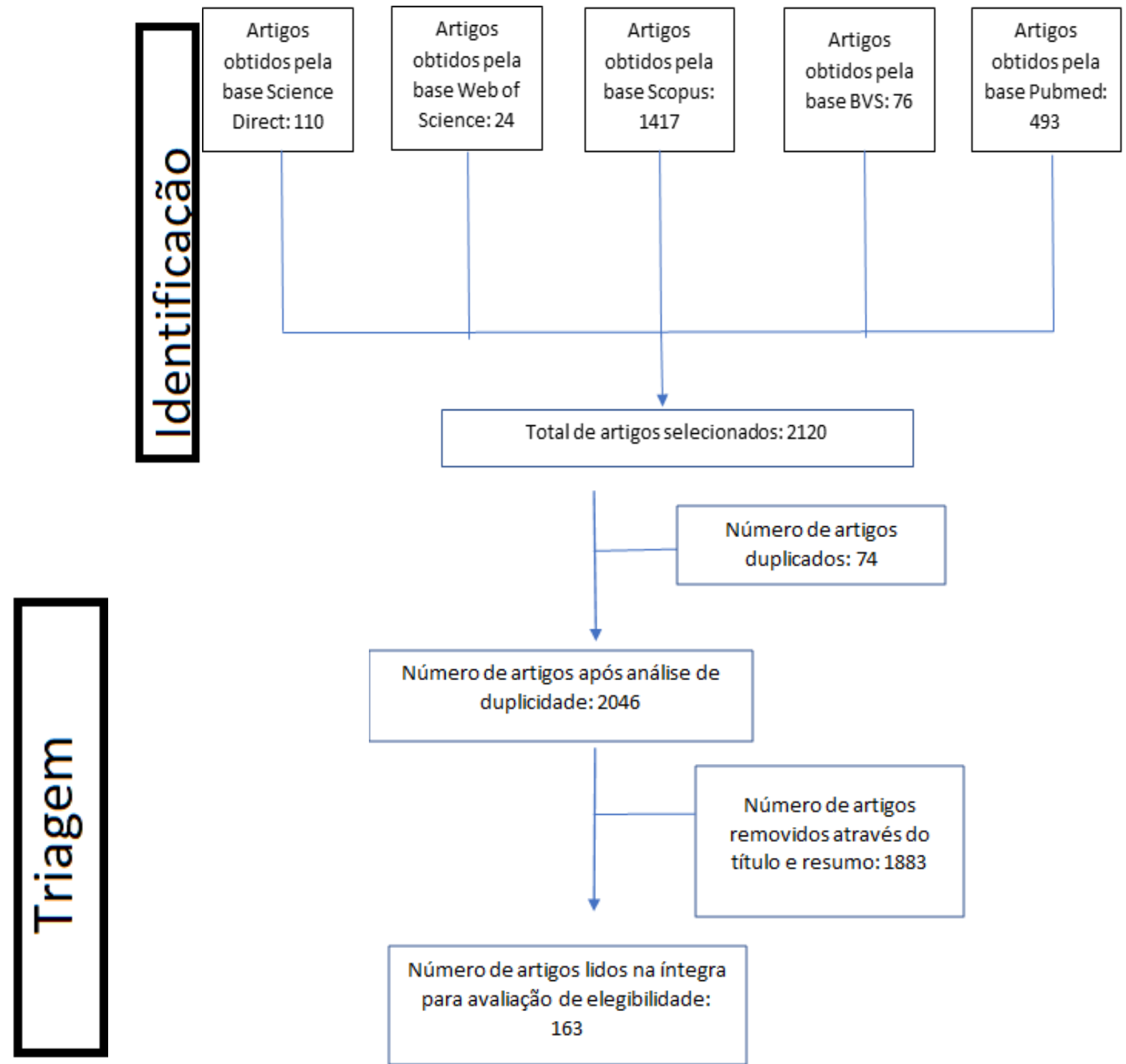

Número de artigos lidos na íntegra para avaliação de elegibilidade:

163

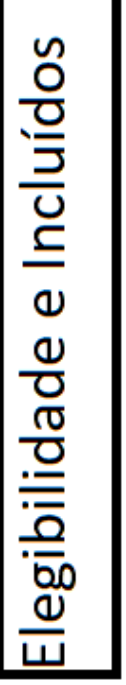

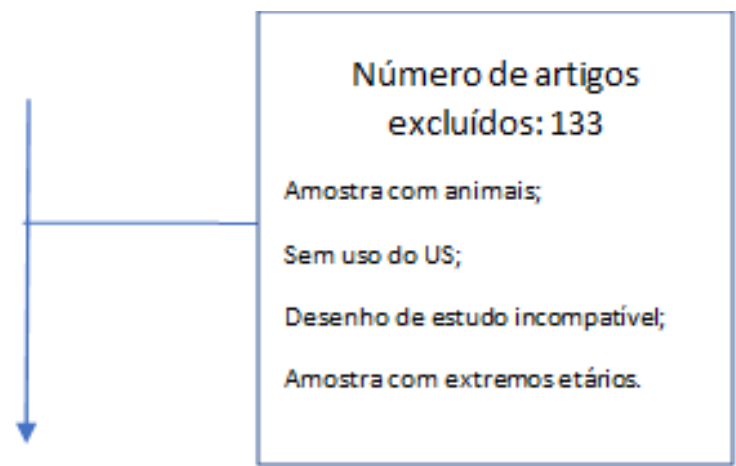

Número de artigos incluídos na revisão: 30

Fonte: Autores. 


\subsection{Validações e comparações com outros métodos}

Os quadros 01, 02 e 03 resumem os principais artigos em que houve comparação direta entre o US e os demais métodos de avaliação da composição corporal. A revisão contemplou pesquisas realizadas em cinco continentes, com maior número de pesquisas desenvolvidas no hemisfério norte, especialmente nos EUA e no Canadá. Brasil e Chile foram os países da América do Sul que realizaram pesquisas com US empregado na composição corporal. Dentre os outros métodos avaliados juntamente com o US, a absormetria de raios-x de dupla energia (DEXA) foi o mais comum, seguido pela ressonância magnética (RNM), pela tomografia computadorizada (TC) e finalmente pela bioimpedância (BIA).

De uma forma geral, a US mostrou boa correlação com os demais métodos de composição corporal. Na avaliação muscular, a avaliação quantitativa com a medida da espessura ou da área muscular, que expressam a massa muscular, apresentou melhores resultados. A avaliação qualitativa pela ecogenicidade muscular, que reflete o grau de lipossubstituição da musculatura, obteve correlações mais fracas. Em relação ao tecido adiposo subcutâneo, muitos trabalhos realizaram medidas em locais similares ao dos avaliados nas medidas das pregas cutâneas, outros focam em locais de avaliação mais simplificada, ambos obtendo bons resultados.

Um dos caminhos para utilização da US é a criação de equações para determinar volume e/ou peso do compartimento muscular. A determinação do volume muscular está relacionada a seu peso, podendo ser calculada a massa muscular regional ou total. O conhecimento do peso da massa muscular ou do percentual de massa muscular do indivíduo traz informações de mais fácil manejo clínico, já que dados provenientes do exame físico e de outros métodos de composição corporal muitas vezes expressam seus resultados dessa mesma forma. Autores validaram equações para o cálculo da massa muscular total e regional em adultos, obtendo forte correlação com a ressonância magnética utilizando medida de 9 grupos musculares ( $r=0,96$ e r=0,91) para homens e mulheres respectivamente. Medindo 6 grupos musculares, também obtiveram forte correlação ( $\mathrm{r}=0,96$ e 0,88$)$ no sexo masculino e feminino. (Sanada et al., 2006). Em outro estudo foi desenvolvida e validada uma equação que utiliza a medida da espessura da musculatura flexora do braço, o comprimento do membro, a idade e o gênero, que pode ser empregada para determinação da massa muscular em uma ampla faixa etária 19 a 77 anos - (Akagi et al., 2010).

Em relação a avaliação do percentual de gordura, também foram desenvolvidas equações para esse fim, uma delas usando o US para medir o tecido adiposo em quatro sítios anatômicos específicos (na região biciptal, triciptal, supraespinhosa e anterior da coxa) comparando o US com o DEXA e obtendo uma forte correlação $\left(\mathrm{R}^{2}=0.879\right)$ dos resultados (O’Neill et al., 2015). Equações que utilizam menor número de locais de medida, avaliando apenas duas regiões corporais, mostram da mesma forma resultados consistentes com a avaliação por DEXA ( $\mathrm{r}=0,947)$ para homens e $(\mathrm{r}=0,909)$ para mulheres (Leahy et al., 2012). Outro grupo testou o desenvolvimento de um protocolo para o cálculo do tecido adiposo pela ultrassonografia derivado do DEXA. O protocolo composto de quatro áreas de avaliação de espessura do tecido adiposo demonstrou associação forte $\mathrm{R}^{2}=$ 0.65 em relação ao DEXA. A adição de covariantes como idade, sexo, IMC no modelo aumentam a acurácia (Paris, et al., 2018).

Uma outra casuística estudou a confiabilidade e a validade da US na avaliação muscular utilizando diferentes transdutores e parâmetros, frente a RNM. Não foram encontradas diferenças significativas em avaliações repetidas da espessura, da área muscular e da ecogenicidade muscular do reto femoral neste estudo. A confiabilidade da espessura e da área muscular do foi excelente tanto para transdutores lineares como para convexos, com coeficiente de correlação interclasse variando de 0.87 a 0.97. O mesmo estudo reporta a confiabilidade moderada para avaliação da ecogenicidade muscular, com esse coeficiente variando de 0.42 a 0.44. Em relação a concordância entre o ultrassom e a ressonância magnética, esta variou de moderado para a espessura do reto femoral (coeficiente de correlação interclasse de 0.45) a excelente para a área muscular (coeficiente de correlação interclasse de 0.92) (Nijholt et al., 2019). A validade da estimativa de espessura muscular também já havia sido reportada em outros trabalhos. (Thomaes et al., 2012; Berger et al., 2015; Ismail et al., 2015). O fato de tanto o transdutor linear como o convexo se mostrarem válidos e reprodutíveis na avaliação muscular, salienta mais um aspecto positivo para a 
estimulação da utilização da US. A possibilidade do uso de diferentes transdutores facilita a avaliação de pacientes com biotipos diversos, contornando a possível limitação técnica em indivíduos com obesidade ou com edema (Belem et al., 2004).

Quanto a reprodutibilidade intra e interobservador, foram demonstrados bons resultados em estudos utilizando a ultrassonografia para avaliação da gordura intra-abdominal e subcutânea, com taxas de reprodutibilidade intraobservador variando de 0.992 a 0.999 e interobservador variando de 0.990 a 0.998 . O coeficiente de correlação da espessura da gordura visceral com a RNM foi de $\mathrm{R}=0.898$ e para gordura subcutânea foi de $\mathrm{R}=0.705$ (Schlecht, et al., 2014). Outro estudo comparou a medida do tecido adiposo visceral realizada pelo US e DEXA com a TC, sendo a ultrassonografia o método que teve melhor correlação com a TC na avaliação da gordura visceral em homens obesos (Berker et al., 2010). Na África do Sul estudo de validação da US na estimativa do tecido adiposo intra-abdominal mostrou maior correlação com a RNM, apresentando coeficiente de correlação de 0.72 no sexo masculino (Rolfe et al., 2011). Este bom desempenho da US na avaliação do tecido adiposo visceral frete aos demais métodos corrobora com o estudo de reprodutibilidade e validação de técnica de medida da espessura da gordura intra-abdominal que obteve resultados bastantes consistentes em comparação a TC, com coeficiente de correlação de Pearson de 0,81 e valor $\mathrm{P}<0,001$. (Stolk et al., 2001).

Quadro 1: Estudos selecionados segundo tipo de método utilizado para avaliação da composição corporal.

\begin{tabular}{|c|c|c|c|c|c|}
\hline \multicolumn{6}{|c|}{ Estudos envolvendo Ultrassonografia (US) e Densitometria (DEXA) } \\
\hline Estudo & $\begin{array}{l}\text { Métodos de } \\
\text { composição } \\
\text { avaliados }\end{array}$ & $\begin{array}{l}\text { Parâmetro da } \\
\text { composição avaliado }\end{array}$ & Amostra & $\begin{array}{l}\text { Correlação obtida } \\
\text { com o US }\end{array}$ & Conclusão do autor \\
\hline $\begin{array}{l}\text { 1. Pineau et al. } \\
\text { (2009) }\end{array}$ & US x DEXA & $\begin{array}{l}\text { Porcentagem de } \\
\text { massa de gordura } \\
\text { entre US e DEXA }\end{array}$ & $\begin{array}{l}93 \text { atletas de } 18 \\
\text { a } 33 \text { anos. }\end{array}$ & $\begin{array}{l}\text { Porcentagem de massa } \\
\text { corporal de gordura } \\
\text { geral. } \mathrm{r}=0.96, \mathrm{R}^{2}= \\
0.97, \mathrm{p}<0.01\end{array}$ & $\begin{array}{l}\text { Correlação acurada, a } \\
\text { despeito do sexo ou demais } \\
\text { variáveis. }\end{array}$ \\
\hline $\begin{array}{l}\text { 2. Pineau et al. } \\
(2010)\end{array}$ & US x DEXA & $\begin{array}{l}\text { Porcentagem de } \\
\text { massa de gordura } \\
\text { entre US e DEXA }\end{array}$ & $\begin{array}{l}94 \text { adolescentes } \\
\text { obesos de } 12 \text { a } \\
19 \text { anos de idade }\end{array}$ & $\begin{array}{l}\text { Porcentagem corporal } \\
\text { de gordura em } \\
\text { homens (DEXA x US) } \\
\left.\mathrm{r}^{2}=0.61, \text { SEE }=2.7\right) \\
\text { Porcentagem coporal } \\
\text { de gordura em } \\
\text { mulheres (DEXA x } \\
\text { US) }\left(\mathrm{r}^{2}=0.94, \text { SEE }=\right. \\
2.3) .\end{array}$ & $\begin{array}{l}\text { US se mostrou comparável } \\
\text { à DEXA, e de forma muito } \\
\text { superior à prega cutânea. }\end{array}$ \\
\hline $\begin{array}{l}\text { 3. Melvin et al. } \\
\text { (2014) }\end{array}$ & US x DEXA & $\begin{array}{l}\text { Área transversa e } \\
\text { ecogenicidade (US) } \\
\text { do Vasto Lateral } \\
\text { versus Massa Magra } \\
\text { de Perna (DEXA) }\end{array}$ & $\begin{array}{l}73 \text { jogadores de } \\
\text { futebol ( } 4 \\
\text { removidos por } \\
\text { lesões) com } \\
\text { idade de } 20 \pm \\
1.1 \text { anos. }\end{array}$ & $\begin{array}{l}\text { Área transversa (US) } \\
\text { x Massa magra } \\
(\mathrm{DEXA}) \mathrm{R}=0.388- \\
0.632, \mathrm{P}=0.01 \\
\text { Ecogenicidade (US) } \mathrm{x} \\
\text { Massa magra de perna } \\
\text { direita (DEXA) } \\
\mathrm{R}=0.213(\mathrm{p}=0.081)\end{array}$ & $\begin{array}{l}\text { Área de corte seccional é } \\
\text { concordante com DEXA, } \\
\text { mas não ecogenicidade. } \\
\text { Ambos US e DEXA podem } \\
\text { ser utilizados para adaptar } \\
\text { dietas e treinamentos para } \\
\text { atletas. }\end{array}$ \\
\hline $\begin{array}{l}\text { 4. Bazzocchi et } \\
\text { al.(2014) }\end{array}$ & US x DEXA & $\begin{array}{l}\text { Vários parâmetros de } \\
\text { gordura abdominal, } \\
\text { como espessura do } \\
\text { subcutâneo, gordura } \\
\text { pré-peritoneal, intra- } \\
\text { abdominal (US) x } \\
\text { Gordura visceral e } \\
\text { subcutânea (DEXA) }\end{array}$ & $\begin{array}{l}250 \text { adultos de } \\
18 \text { a } 70 \text { anos de } \\
\text { idade }\end{array}$ & $\begin{array}{l}\text { Espessura intra- } \\
\text { abdominal (US) e } \\
\text { Gordura visceral } \\
\text { (DEXA) r=0.754, } \\
\text { p<000.1. } \\
\text { Espessura máxima } \\
\text { subcutânea (US) x } \\
\text { Massa de gordura }\end{array}$ & $\begin{array}{l}\text { A espessura intra- } \\
\text { abdominal foi o melhor } \\
\text { parâmetro do US para } \\
\text { avaliar a gordura visceral } \\
\text { pelo DEXA; assim como a } \\
\text { espessura máxima } \\
\text { subcutânea está para a } \\
\text { Massa de gordura geral } \\
\text { (DEXA). Contudo, outros }\end{array}$ \\
\hline
\end{tabular}


Research, Society and Development, v. 11, n. 2, e56111226221, 2022

(CC BY 4.0) | ISSN 2525-3409 | DOI: http://dx.doi.org/10.33448/rsd-v11i2.26221

\begin{tabular}{|c|c|c|c|c|c|}
\hline & & & & $\begin{array}{l}\text { geral }(\mathrm{DEXA}) \mathrm{r}= \\
0.798, \mathrm{p}<0.0001 . \\
\text { Índice de parede de } \\
\text { gordura (US) x Massa } \\
\text { de gordura geral } \\
\text { (DEXA) p }>0,025 \\
\text { (sem significância) }\end{array}$ & $\begin{array}{l}\text { parâmetros não guardam } \\
\text { boas relações com o DEXA. }\end{array}$ \\
\hline $\begin{array}{l}\text { 5. O’Neill et al. } \\
\text { (2015) }\end{array}$ & US x DEXA & $\begin{array}{l}\text { Tecido adiposo } \\
\text { subcutâneo (US) x } \\
\text { Massa de gordura } \\
\text { (DEXA) }\end{array}$ & $\begin{array}{l}67 \text { atletas de } 17 \\
\text { a } 33 \text { anos de } \\
\text { idade. }\end{array}$ & $\begin{array}{l}\text { Profundidade do } \\
\text { tecido adiposo } \\
\text { subcutâneo (US) em } 4 \\
\text { áreas versus Massa de } \\
\text { gordura (DEXA) } \\
\mathrm{R}^{2}=0.879 \mathrm{p}<0.001 . \\
\text { Profundidade do } \\
\text { mesmo tecido em } 7 \\
\text { áreas (US) versus } \\
\text { massa de gordura } \\
\text { (DEXA) } \\
\text { (R2=0.749) }\end{array}$ & $\begin{array}{l}\text { No público citado, o } \\
\text { modelo de } 4 \text { áreas pelo US } \\
\text { foi efetivo para medir a } \\
\text { Massa de gordura de forma } \\
\text { comparável ao DEXA. }\end{array}$ \\
\hline $\begin{array}{l}\text { 6. Trexler et al. } \\
\text { (2015) }\end{array}$ & US x DEXA & $\begin{array}{l}\text { Área transversa e } \\
\text { ecogenicidade (US) } \\
\text { do Vasto Lateral } \\
\text { versus Massa Magra } \\
\text { de Perna (DEXA) }\end{array}$ & $\begin{array}{l}15 \text { ginastas do } \\
\text { sexo feminino } \\
\text { entre } 18 \text { e } 21 \\
\text { anos. }\end{array}$ & $\begin{array}{l}\text { Área transversa } x \\
\text { ecogenicidade } \\
R=0,637(p<0,01) \\
\text { Parâmetros do US } x \\
\text { Parâmetros do DEXA } \\
\text { e performance } \\
R=0.016-0.344 \\
(p>0,05)\end{array}$ & $\begin{array}{l}\text { Dados do US concordam } \\
\text { inversamente entre si, mas } \\
\text { não se correlacionam com } \\
\text { DEXA e performance; } \\
\text { talvez em razão do N } \\
\text { pequeno. }\end{array}$ \\
\hline $\begin{array}{l}\text { 7. Roelofs et al. } \\
\text { (2015) }\end{array}$ & US x DEXA & $\begin{array}{l}\text { Área transversa e } \\
\text { ecogenicidade (US) } \\
\text { do Vasto Lateral } \\
\text { versus Massa Magra } \\
\text { de Perna (DEXA) }\end{array}$ & $\begin{array}{l}36 \text { atletas de } \\
\text { corrida, sendo } \\
21 \text { masculinos } \\
(19.7 \pm 1.2 \\
\text { anos) e } 15 \\
\text { femininas ( } 19.3 \\
\pm 1.3 \text { anos) }\end{array}$ & $\begin{array}{l}\text { Área transversa (US) } \\
\text { x Massa magra de } \\
\text { perna (DEXA) } \\
\text { Homens: } \mathrm{R}=0.66 \text {, } \\
\mathrm{p}=0.001 . \\
\text { Mulheres: } \mathrm{R}=0.54, \mathrm{p} \\
=0.03 .\end{array}$ & $\begin{array}{l}\text { Dados do US e DEXA } \\
\text { concordam, e podem ser } \\
\text { usados para melhorar } \\
\text { performance e prevenir } \\
\text { lesões. }\end{array}$ \\
\hline $\begin{array}{l}\text { 8. Paris et al. } \\
(2018)\end{array}$ & US x DEXA & $\begin{array}{l}\text { Adiposidade corporal } \\
\text { total (a partir de US } \\
\text { em } 4 \text { áreas) x Massa } \\
\text { Magra (DEXA) }\end{array}$ & $\begin{array}{l}94 \text { adultos } \\
\text { dentre } 24 \text { a } 70 \\
\text { anos. }\end{array}$ & $\begin{array}{l}\text { Adiposidade corporal } \\
\text { total US x DEXA: R2 } \\
=0.65, \mathrm{p}<0.001 .\end{array}$ & $\begin{array}{l}\text { Há boa correlação com o } \\
\text { modelo de } 4 \text { áreas, mas com } \\
\text { o novo protocolo os } \\
\text { resultados são melhores. }\end{array}$ \\
\hline $\begin{array}{l}\text { 9. Fortin et al. } \\
\text { (2019) }\end{array}$ & US x DEXA & $\begin{array}{l}\text { Área transversa, } \\
\text { espessura e } \\
\text { ecogenicidade do } \\
\text { músculo multifidus } \\
\text { do dorso (US) versus } \\
\text { massa magra } \\
\text { (DEXA) }\end{array}$ & $\begin{array}{l}32 \text { jogadores de } \\
\text { hóquei, } \\
\text { mulheres e } \\
\text { homens, de } 21.4 \\
\pm 1.4 \text { anos. }\end{array}$ & $\begin{array}{l}\text { Área transversa (US) } \\
\text { x massa magra } \\
(\text { DEXA) r=0.49, } \\
\text { p<0.004. } \\
\text { Ecogenicidade (US) x } \\
\text { massa magra } r=0.60, \\
\text { p }<0.001) .\end{array}$ & $\begin{array}{l}\text { Houve correlação entre } \\
\text { medidas do DEXA e US. } \\
\text { Pode-se medir esse músculo } \\
\text { como um programa de } \\
\text { screening de risco de lesões } \\
\text { no futuro. }\end{array}$ \\
\hline $\begin{array}{l}\text { 10. Pineau et al. } \\
\text { (2019) }\end{array}$ & US x DEXA & $\begin{array}{l}\text { Porcentagem de } \\
\text { massa de gordura } \\
\text { entre DEXA e US } \\
\text { (obtida a partir de } \\
\text { diferentes equações } \\
\text { de predição) }\end{array}$ & $\begin{array}{l}100 \text { atletas de } \\
\text { variadas } \\
\text { categorias de } 18 \\
\text { a } 30 \text { anos. }\end{array}$ & $\begin{array}{l}\text { Porcentagem de massa } \\
\text { corporal de gordura } \\
\text { geral. } \\
\text { Equação } 06: \rho c \\
=0.942, \mathrm{P}<0.05 \\
\text { SEE }=1.52 \text {. }\end{array}$ & $\begin{array}{l}\text { Boa correlação, a ser } \\
\text { testada em outros grupos } \\
\text { para posterior validação e } \\
\text { difusão. }\end{array}$ \\
\hline
\end{tabular}




\begin{tabular}{|l|l|l|l|l|l|}
$\begin{array}{l}\text { 11. Schryver et } \\
\text { al. } \\
(2020)\end{array}$ & US x DEXA & $\begin{array}{l}\text { Área transversa e } \\
\text { ecogenicidade do } \\
\text { músculo multifidus } \\
\text { do dorso (US) versus } \\
\text { massa magra } \\
\text { (DEXA) }\end{array}$ & $\begin{array}{l}41 \text { jogadores de } \\
\text { futebol de } 21 \pm \\
1.1 \text { anos. }\end{array}$ & $\begin{array}{l}\text { Área transversa (US) } \\
\text { x massa magra } \\
\text { (DEXA) lean body } \\
\text { mass r=0.51, } \\
\text { p<0.001) }\end{array}$ & $\begin{array}{l}\text { Medidas do US e DEXA se } \\
\text { correlacionam, e podem } \\
\text { servir de ferramenta para } \\
\text { prática desportiva. }\end{array}$ \\
& & & & \\
\hline
\end{tabular}

Fonte: Autores.

Quadro 2: Estudos selecionados segundo tipo de método comparado.

\begin{tabular}{|c|c|c|c|c|c|}
\hline \multicolumn{6}{|c|}{ Estudos envolvendo Ultrassonografia (US) e Ressonância Nuclear Magnética (RNM) } \\
\hline Estudo & $\begin{array}{l}\text { Métodos de } \\
\text { composição } \\
\text { avaliados }\end{array}$ & $\begin{array}{l}\text { Parâmetro da } \\
\text { composição avaliado }\end{array}$ & Amostra & $\begin{array}{l}\text { Correlacão obtida } \\
\underline{\text { com o US }}\end{array}$ & Conclusão do autor \\
\hline $\begin{array}{l}\text { 1. Rolfe et al } \\
\text { (2011) }\end{array}$ & US x RNM & $\begin{array}{l}\text { Gordura subcutânea e } \\
\text { gordura visceral entre } \\
\text { US e RNM. }\end{array}$ & $\begin{array}{l}100 \\
\text { adolescentes } \\
\text { negros e } \\
\text { saudáveis, de } 18 \\
\text { e } 19 \text { anos. }\end{array}$ & $\begin{array}{l}\text { Espessura da gordura } \\
\text { visceral US x RNM: } \\
\mathrm{R}=0.72, \mathrm{p}<0.0\end{array}$ & $\begin{array}{l}\text { US é altamente comparável } \\
\text { à RNM; ademais, foi criada } \\
\text { uma equação de predição } \\
\text { para melhorá-la. }\end{array}$ \\
\hline $\begin{array}{l}\text { 2. Schlecht et } \\
\text { al. } \\
(2014)\end{array}$ & US x RNM & $\begin{array}{l}\text { Gordura subcutânea e } \\
\text { visceral no US versus } \\
\text { RNM }\end{array}$ & $\begin{array}{l}127 \text { adultos } \\
\text { entre } 20 \text { a } 70 \\
\text { anos de idade. }\end{array}$ & $\begin{array}{l}\text { Espessura de gordura } \\
\text { visceral pelos dois } \\
\text { métodos: } r=0.898, \\
\mathrm{p}<0.001 . \\
\text { Espessura de gordura } \\
\text { subcutânea pelos dois } \\
\text { métodos: } r=0.705, \\
\mathrm{p}<0.001 .\end{array}$ & $\begin{array}{l}\text { Os dados do US e RNM são } \\
\text { comparáveis, inclusive para } \\
\text { adultos com IMC normal, } \\
\text { sendo o US um método } \\
\text { também de boa } \\
\text { reprodutibilidade. }\end{array}$ \\
\hline $\begin{array}{l}\text { 3. Berger et al. } \\
(2015)\end{array}$ & US x RNM & $\begin{array}{l}\text { Ecogenicidade e } \\
\text { espessura do músculo } \\
\text { reto femoral (US) } \\
\text { versus Massa magra } \\
\text { (DEXA) }\end{array}$ & $\begin{array}{l}4 \text { adultos, com } \\
\text { idade de } 32.4 \pm \\
7.1 \text { anos }\end{array}$ & $\begin{array}{l}\text { Espessura (US) } \mathrm{x} \\
\text { Massa magra } \\
\text { apendicular (DEXA) } \\
\mathrm{IC}=0.578-0.785 . \\
\mathrm{P}<0,01 . \\
\text { Ecogenicidade (US) x } \\
\text { Massa magra } \\
\text { apendicular (DEXA) } \\
\mathrm{IC}=0.606-0.299 . \\
\mathrm{P}<0.01 .\end{array}$ & $\begin{array}{l}\text { Boa correlação entre US e } \\
\text { DEXA. Portanto, US pode } \\
\text { ser utilizado para estimar a } \\
\text { massa muscular de } \\
\text { membros inferiores }\end{array}$ \\
\hline $\begin{array}{l}\text { 4. Belavy et al. } \\
\text { (2015) }\end{array}$ & US x RNM & $\begin{array}{l}\text { Espessura e área de } \\
\text { músculos do dorso } \\
\text { medidas pelo US e } \\
\text { RNM }\end{array}$ & $\begin{array}{l}23 \text { adultos do } \\
\text { sexo masculino, } \\
\text { entre 21-45 anos }\end{array}$ & $\begin{array}{l}\text { Área do músculo } \\
\text { multífido pelo US e } \\
\text { RNM } R=0.36(0.06- \\
0.67) \mathrm{p}<0,05 \\
\text { Espessura do músculo } \\
\text { eretor da coluna } \\
\mathrm{R}=0.52(0.14-0.77)\end{array}$ & $\begin{array}{l}\text { Medidas do US concordam } \\
\text { com aquelas da RNM, } \\
\text { apesar da força de } \\
\text { associação ser menor para o } \\
\text { músculo multífido }\end{array}$ \\
\hline $\begin{array}{l}\text { 5. Nijholt et al. } \\
\text { (2019) }\end{array}$ & US x RNM & $\begin{array}{l}\text { Área transversa e } \\
\text { espessura do músculo } \\
\text { reto femoral entre US } \\
\text { e RNM. }\end{array}$ & $\begin{array}{l}40 \text { adultos entre } \\
18 \text { e } 65 \text { anos, } \\
\text { mediana de } 32.5 \\
\text { anos }\end{array}$ & $\begin{array}{l}\text { Área transversa US x } \\
\text { RNM: ICC }=0.62 ; \\
95 \% \text { CI: } 0.031 \text { - } \\
0.919) .\end{array}$ & $\begin{array}{l}\text { Ótima correlação entre os } \\
\text { métodos, apesar de } \\
\text { preliminar. }\end{array}$ \\
\hline $\begin{array}{l}\text { 6. Akagi et al. } \\
(2020)\end{array}$ & US $x$ RNM & $\begin{array}{l}\text { Espessura dos } \\
\text { músculos flexores do } \\
\text { cotovelo (US) x } \\
\text { Volume dos mesmos } \\
\text { músculos (RNM) }\end{array}$ & $\begin{array}{l}147 \text { adultos, } \\
\text { dentre mulheres } \\
\text { e homens de } 19 \\
\text { a } 77 \text { anos. }\end{array}$ & $\begin{array}{l}\text { Relação entre o } \\
\text { volume obtido } \\
\text { diretamente pela } \\
\text { RNM e aquele volume } \\
\text { obtido pela equação } \\
\text { de predição (usando } \\
\text { US) } \\
\mathrm{r}=0.448 \text { (P < } 0.001 \text { ) }\end{array}$ & $\begin{array}{l}\text { As medidas pelo US, } \\
\text { quando associadas a idade e } \\
\text { sexo (equação de predição) } \\
\text { se correlacionam com o } \\
\text { volume obtido pela RNM. }\end{array}$ \\
\hline
\end{tabular}


Quadro 3: Estudos selecionados segundo tipo de método comparado.

\begin{tabular}{|c|c|c|c|c|c|}
\hline \multicolumn{6}{|c|}{ Estudos envolvendo Ultrassonografia (US) e Tomografia Computadorizada (TC) } \\
\hline Estudo & $\begin{array}{l}\text { Métodos de } \\
\text { composição } \\
\underline{\text { avaliados }}\end{array}$ & $\begin{array}{l}\text { Parâmetro da } \\
\text { composicão avaliado }\end{array}$ & Amostra & $\begin{array}{l}\text { Correlacão obtida } \\
\text { com o US }\end{array}$ & Conclusão do autor \\
\hline $\begin{array}{l}\text { 1. Simon et al. } \\
(2009)\end{array}$ & US $x$ TC & $\begin{array}{l}\text { Gordura subcutânea e } \\
\text { gordura visceral entre } \\
\text { US e TC. }\end{array}$ & $\begin{array}{l}\text { Gordura } \\
\text { subcutânea e } \\
\text { gordura } \\
\text { visceral entre } \\
\text { US e TC. }\end{array}$ & $\begin{array}{l}\text { Adiposidade } \\
\text { subcutânea total US } \\
X \text { TC. } R=0.61, \\
\text { p }<0,05 . \text { Valor de } \\
\text { referência seria } \\
\geq 0.65 .\end{array}$ & $\begin{array}{l}\text { Não houve boa correlação } \\
\text { entre US e TC; o que } \\
\text { pode ser dever ao } \\
\text { tamanho amostral. }\end{array}$ \\
\hline $\begin{array}{l}\text { 2. Berker et al. } \\
(2010)\end{array}$ & US x TC & $\begin{array}{l}\text { Gordura subcutânea e } \\
\text { gordura visceral (US) } \\
\text { versus Área de tecido } \\
\text { subcutâneo (TC) }\end{array}$ & $\begin{array}{l}104 \text { adultos } \\
\text { saudáveis, com } \\
\text { idades entre } 19 \\
\text { a } 58 \text { anos. }\end{array}$ & $\begin{array}{l}\text { Espessura de gordura } \\
\text { visceral (US) x Área } \\
\text { de gordura visceral } \\
\text { (TC): } r=0.823 \text {, p< } \\
0.001) .\end{array}$ & $\begin{array}{l}\text { Houve boa correlação } \\
\text { geral, mas quando há } \\
\text { estratificação por IMC em } \\
\text { alguns grupos isso se } \\
\text { perde; o que talvez é } \\
\text { reflexo da restrição } \\
\text { amostral. }\end{array}$ \\
\hline $\begin{array}{l}\text { 3. Paris et al. } \\
\text { (2016) }\end{array}$ & US $\mathrm{x}$ TC & $\begin{array}{l}\text { Espessura do } \\
\text { músculo quadríceps } \\
\text { (US) versus Área } \\
\text { transversa de } \\
\text { músculo a nível de } \\
\text { L3 (TC) }\end{array}$ & $\begin{array}{l}204 \text { pacientes } \\
\text { em unidade } \\
\text { de terapia } \\
\text { intensiva (18- } \\
96 \text { anos }\end{array}$ & $\begin{array}{l}\text { Média de espessura } \\
\text { de quadríceps (US) x } \\
\text { TC }(\mathrm{r}=0.45, \\
\mathrm{p}<0.001) \\
\text { Grupos sem } \\
\text { correlação } \\
\text { separadamente: } \\
\text { mulheres jovens } \\
(0,13) \text { homens idosos } \\
(0,24) \text { e mulheres } \\
\text { idosas }(0,26)\end{array}$ & $\begin{array}{l}\text { Isoladamente, o US pode } \\
\text { não ser um bom preditor } \\
\text { da massa muscular pela } \\
\text { TC. Contudo, se } \\
\text { associado a preditores } \\
\text { como IMC, idade e sexo, } \\
\text { poderia ser válido; sendo } \\
\text { necessário um novo } \\
\text { protocolo. }\end{array}$ \\
\hline
\end{tabular}

Fonte: Autores.

\subsection{Técnicas utilizadas e locais de medida}

Observou-se uma grande variabilidade dos sítios de avaliação tanto do tecido muscular quanto do tecido adiposo. O gráfico 1 e 2 organizam os artigos conforme o sítio de avaliação da composição corporal através do US, bem como as técnicas utilizadas para esse objetivo, de modo a aproximar os estudos com delineamento semelhante. 
Research, Society and Development, v. 11, n. 2, e56111226221, 2022

(CC BY 4.0) | ISSN 2525-3409 | DOI: http://dx.doi.org/10.33448/rsd-v11i2.26221

Gráficos 1 e 2: Estudos selecionados segundo o local de avaliação e a técnica de mensuração.

Gráfico 1.

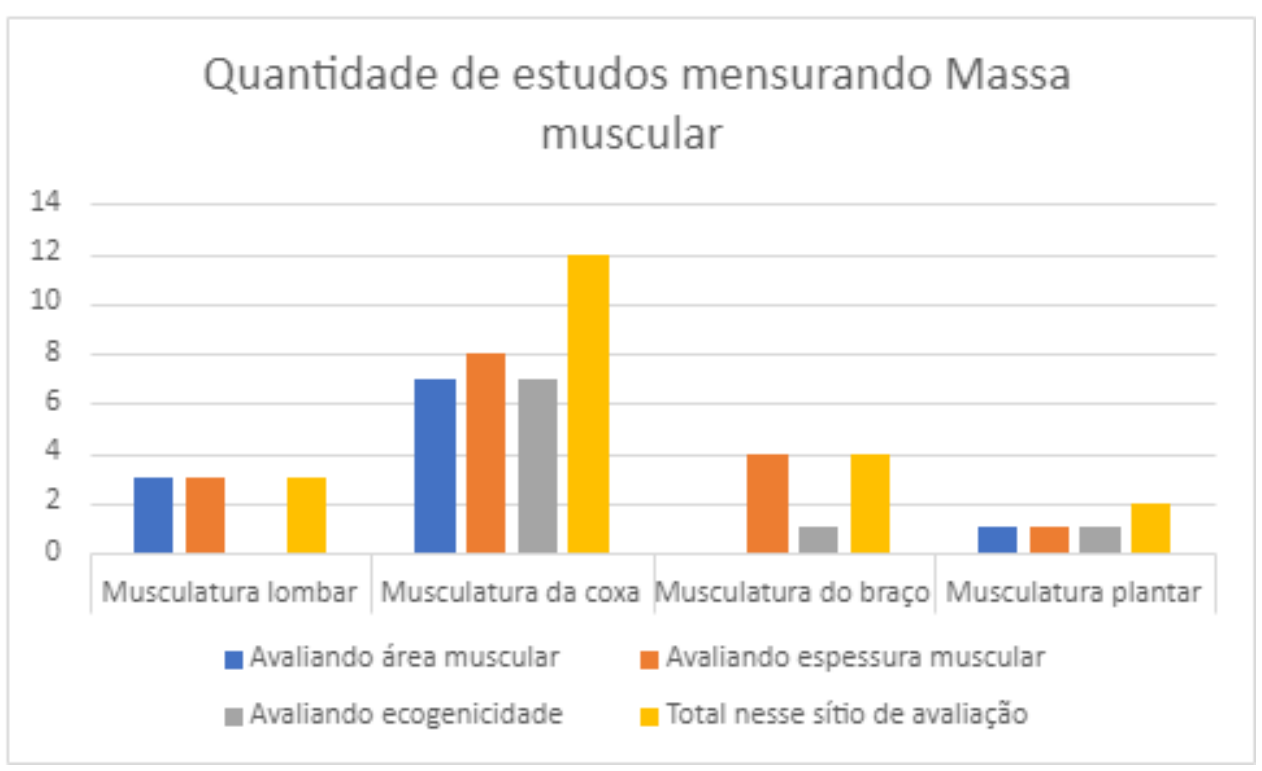

Fonte: Autoria própria.

Gráfico 2.

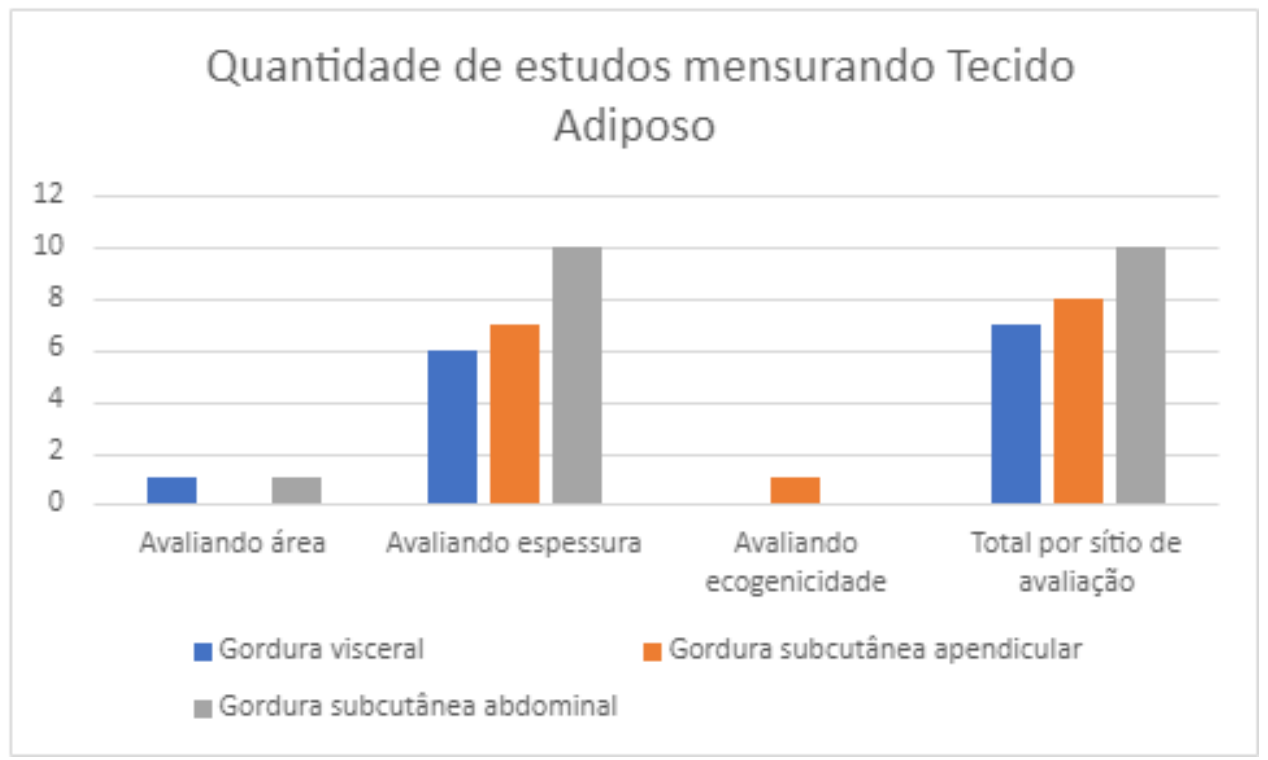

Fonte: Autoria própria.

A utilização de diferentes sítios de medida nas pesquisas em parte foi relacionada a alguns estudos direcionarem a avaliação para regiões que possivelmente estariam afetados pela patologia de estudo, como o caso da avaliação da musculatura lombar em esportistas com dor lombar, ou da quantificação da gordura visceral em portadores de alterações metabólicas e cardiovasculares. Contudo, alguns sítios anatômicos podem ser especialmente de difícil acesso ao US, limitando seu uso em algumas regiões. Em um trabalho recente, os autores mostraram em média correlação moderada entre a ultrassonografia e a ressonância magnética na avaliação da musculatura paravertebral, com melhor correlação entre a espessura do eretor da espinha 
em comparação com a área do músculo multifido. Foi atribuída esta correlação mais pobre do músculo multifido pelo fato das estruturas anatômicas de reparo e orientação para realização das imagens serem menos nítidas e pior definidas junto a esse músculo que para o eretor da espinha (Belavy et al., 2015). A importância da escolha do sítio de medida não deve estar relacionada somente a região de interesse, devendo ser consideradas estruturas de mais fácil acesso ao US, facilitando a obtenção de imagens adequadas para mensuração.

Os autores quase invariavelmente têm adotado técnicas que utilizam mínima compressão possível do transdutor sobre a pele, com objetivo de evitar deformação da musculatura ou do tecido adiposo, prejudicando as medidas. Em uma dessas casuísticas, os autores atribuíram a baixa correlação da medida da espessura do quadríceps realizada pela ultrassonografia comparada a tomografia computadorizada no seu estudo, principalmente pelo fato de terem utilizado técnica de exame efetuando maior compressão possível do transdutor sobre a área avaliada, que segundo eles, pode ter gerado uma variabilidade de medidas que confundiu as correlações. Também atribuem a baixa correlação do ultrassom com a tomografia ao fato de terem realizado os exames de US e TC em datas diferentes, podendo ter havido mudanças na massa muscular ou alterações relacionadas a edema neste período (Paris et al., 2016). Assim como a compressão dos tecidos pode causar erros nas medidas do US, a realização de exercícios físicos antes das medidas de composição corporal pelo US e por outros métodos de avaliação da composição corporal podem ser alterados. Alguns trabalhos mostraram aumento da espessura e da ecogenicidade muscular na ultrassonografia e aumento da área e redução da densidade muscular na tomografia em exames seriados após 24, 48 horas e mesmo 72 horas após a realização de exercícios físicos (Rowe et al., 2019).

\subsubsection{Avaliação da ecogenicidade muscular e a utilização de softwares:}

A forma da avaliação da ecogenicidade muscular, que traduz o grau de lipossubstituição da musculatura, de uma forma geral diferiu apenas em uma das pesquisas (Pettersson et al., 1989), na qual os autores utilizaram um método exclusivamente visual, sem uso de softwares, através da escala de Heckmaate-Dubowitz (Heckmatt et al., 1984). Os demais estudos avaliando a ecogenicidade, tratando-se também de estudos mais recentes, deram preferência para métodos automatizados para essa avaliação, reduzindo assim a possibilidade de variação interobservador, diminuindo também a dependência da experiência do operador da ultrassonografia (Roelofs et al., 2016; Trexler et al., 2015; Roelofs et al., 2015; Melvin et al., 2014; Schryver et al., 2020). Um dos softwares utilizados foi o Image J, sendo de domínio público, disponível em imageJ.inh.gov para download para Windows, Mac, Ios e Linox. O software pode entre outros ser utilizado para cálculo de área e da contagem de pixels na imagem, refletindo, portanto, a ecogenicidade na escala de cinza observada nas imagens da ultrassonografia. Os autores (Melvin et al., 2014; Schryver et al., 2020) utilizaram o software do Osirix versão 9.0, também possibilitando a quantificação da escala de cinza do tecido muscular avaliado. Os pesquisadores dessas casuísticas procuraram seguir protocolos bem definidos e reprodutíveis, com o desenho cuidadoso por parte do operador da área da musculatura a ser calculada e avaliada, seguindo mais próximo possível do plano facial. As avaliações foram precedidas pela calibração do software para mensuração da ecogenicidade muscular. (Trexler et al., 2015; Roelofs et al., 2015; Melvin et al., 2014).

Importante ressaltar que, para uma avaliação adequada do software na estimativa da ecogenicidade, procede-se uma calibração antes de sua utilização. Os parâmetros de frequência, ganho e profundidade do foco do aparelho de ultrassonografia permanecem constantes durante a avaliação. Procede-se então a medida da escala de cinza dos pixels da imagem, sendo graduados entre 0 e 255 do menos ecogênico para o mais ecogênico. Já foi testada a reprodutibilidade da medida da área muscular e da medida da ecogenicidade muscular com o coeficiente correlação interclasse de 0.92 para a medida da área e de 0.91 para a ecogenicidade muscular (Trexler et al., 2015). Um estudo prévio mostrou que a ecogenicidade muscular avaliada pela US tem correlação significativa com o conteúdo de gordura no músculo vasto lateral e no bíceps femoral medida pela ressonância magnética - P menor que 0.05 para o vasto lateral e P menor que 0.001 para o bíceps femoral- (Akima et al., 2016). 


\section{3 Áreas de aplicabilidade}

O Gráfico 3 separa os diferentes trabalhos conforme a área de aplicabilidade para a qual a avaliação da composição corporal foi utilizada.

Gráfico 3: Estudos selecionados por área de aplicabilidade em que se aplica a composição corporal.

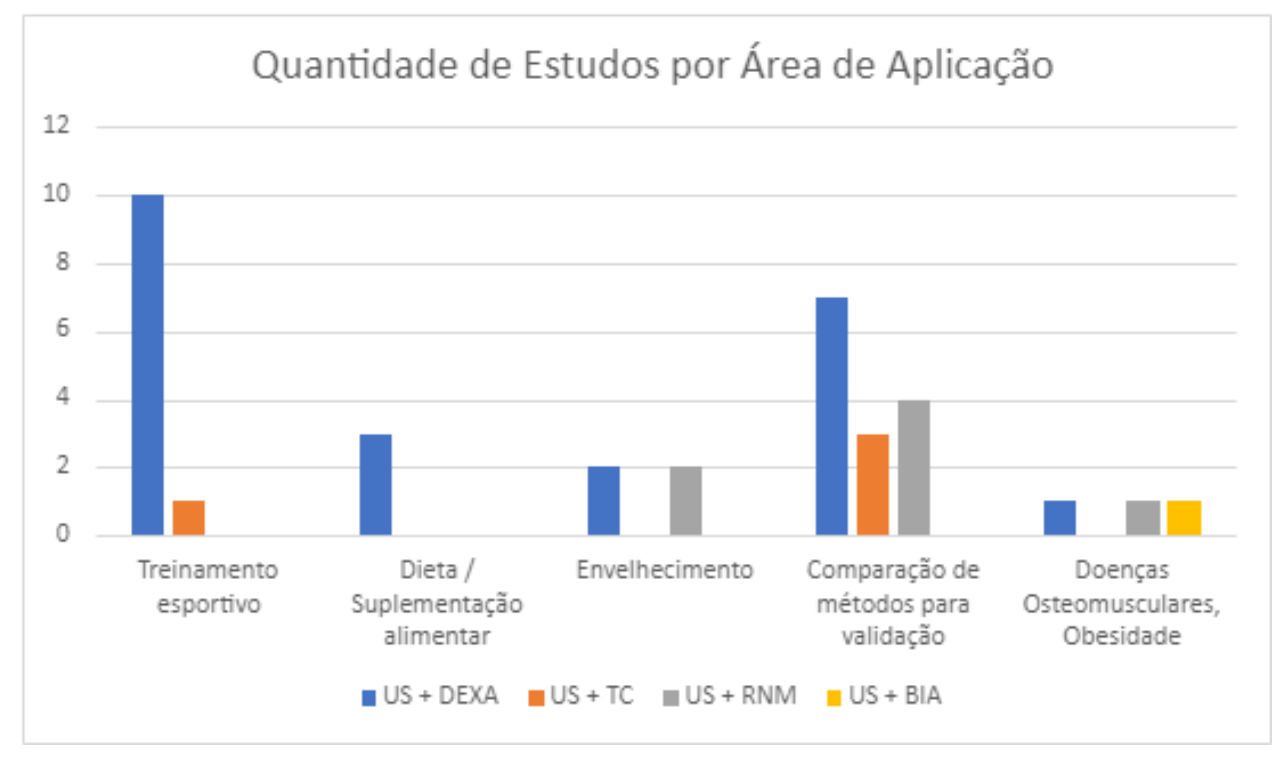

Fonte: Autoria própria.

A possibilidade de a ultrassonografia acessar a musculatura em diferentes segmentos do corpo facilita a avaliação de grupamentos musculares que possam estar relacionados a patologia ou a população estudada, permitindo assim um estudo mais específico. Outra possibilidade é a avaliação muscular em regiões anatômicas mais facilmente acessíveis e representativas da massa muscular total. Ao estudar a musculatura lombar de jogadores de futebol portadores dor lombar, um trabalho mostrou que a espessura da musculatura lombar era significativamente menor nos indivíduos que relataram dor lombar nos três meses anteriores ao estudo, em comparação ao grupo controle. A área muscular também foi significativamente correlacionada com o peso, altura e a massa magra medida pelo DEXA. A ecogenicidade por sua vez foi fortemente relacionada com o percentual de gordura corporal (Schryver et al., 2020). Achados similares também foram encontrados ao estudarem jogadores de hockey no gelo com dor lombar. A espessura muscular lombar foi significativamente menor em jogadores com dor lombar, encontrando ainda assimetria da musculatura paravertebral em comparação a musculatura contralateral nestes atletas (Fortin et al., 2019). No músculo vasto lateral de atletas de futebol americano observou-se que jogadores da linha de defesa apresentavam uma área muscular maior que os jogadores de outras posições, evidenciando a utilidade do US em caracterizar diferenças do volume muscular dos atletas de esportes coletivos, podendo traduzir tendências ou biotipos mais favoráveis frente à sua função no esporte (Melvin et al., 2014). Trata-se de uma aplicação útil tanto no acompanhamento de treinamentos quanto na seleção de atletas mais aptos a atuar em cada posição no esporte.

A avaliação muscular pela ultrassonografia identificou diferença significativa da área da musculatura do vasto lateral também em outro estudo, que comparou o período pré e pós-temporada de competição de mergulhadores e nadadores. Foi observado aumento da área muscular após o período de treinamento intenso. A ecogenicidade muscular também reduziu comparativamente neste período. Resultados consistentes com o esperado aumento de massa muscular e redução do conteúdo adiposo após o período de treinamento (Roelofs et al., 2016). No Brasil, alguns autores se propuseram a estudar o efeito de treinamentos musculares em homens adultos, e observaram concordância na medida da espessura muscular dos membros superiores e dos membros inferiores com o DEXA, demonstrando aumento da espessura muscular e da massa livre de gordura 
após os programas de treinamento (Avelar et al., 2019).

O fato de o US ser um método livre de radiação ionizante portanto, seguro para avaliações seriadas e pelo seu baixo custo comparado a outras técnicas de imagem, fazem com que seja uma boa opção para avaliação dos resultados de programas alimentares, como a suplementação em esportistas. Alguns autores encontraram aumento da área muscular e da espessura muscular no grupo suplementado com blend de trufas e extrato de maçã frente ao grupo que utilizou placebo, após os treinamentos de resistência (Joy et al., 2015). Paralelamente, outro grupo de estudo ao avaliar suplementação proteica durante três meses demonstrou ganho de massa magra total e nos membros superiores, não encontrando diferença significativa nos músculos dos membros inferiores (Reidy et al., 2016). A US também foi usada para avaliar o efeito de ganho muscular com suplementação de Whey Protein, demonstrando ganho de massa muscular após o programa de treinamento, mas sem diferença significativa entre o grupo suplementado e o grupo que utilizou placebo (Weisgarber et al., 2012).

Patologias que cursem com alterações do tecido muscular podem ser examinadas com US. Um estudo abordando uma miopatia congênita realizou avaliação da musculatura da coxa em relação a sua ecogenicidade, encontrando um envolvimento desse grupo muscular. A ecogenicidade muscular foi anormalmente aumentada nos portadores da patologia em relação ao grupo controle. $\mathrm{O}$ achado ultrassonográfico estava em concordância com os achados da tomografia computadorizada, que revelou baixa densidade muscular, indicando lipossubstituição. A ressonância magnética demonstrou também sinais de degeneração gordurosa da musculatura (Pettersson et al., 1989).

No estudo do envelhecimento, o ultrassom mostra boa capacidade em reconhecer alterações relacionadas à senescência com redução da massa muscular, demonstrando o volume do quadríceps femoral menor em pacientes com idade mais avançada em comparação com adultos jovens. Também o conteúdo de gordura intramuscular avaliado na região posterior da coxa é maior em idosos do que em adultos jovens (Hiokia et al., 2020). Um outro trabalho demonstrou que idosos apresentavam menos massa muscular e piores parâmetros musculares que os adultos. Os idosos com T-score (-2) de força muscular tinham significativamente maior ecogenicidade muscular, retratando assim lipossubstituição. Também os idosos com T-score (-2) no teste de caminhada tinham menores espessuras musculares, refletindo menor massa muscular (Berger et al., 2015).

Sobre a composição corporal aplicada a doenças metabólicas, sabe-se que a associação da gordura visceral com alterações cardiovasculares e metabólicas tem sido estudada por muitos autores. Alguns autores ao mensurar o tecido adiposo visceral e subcutâneo encontraram uma grande relação da proteína $C$ relativa com o volume de gordura visceral medida pela ultrassonografia em pacientes submetidos a cirurgia bariátrica (Carbone et al., 2015). A correlação da gordura visceral com testes bioquímicos encontrada nesse estudo está em concordância com estudos prévios, que indicam que essa associação pode estar presente mesmo antes da idade adulta, sendo encontrada associação estatisticamente significativa com o diagnóstico de síndrome metabólica ( $\mathrm{p}=0,037)$,índice de massa corporal $(\mathrm{p}<0,001)$, níveis elevados de triglicerídeos $(\mathrm{p}=0,012)$, redução dos níveis plasmáticos de HDL ( $\mathrm{p}=0,034)$ e aumento da pressão arterial sistêmica $(\mathrm{p}=0,023)$. (Novais et al., 2018)

Em alguns grupos específicos, como no pós-parto, a medida da gordura intra-abdominal por ultrassonografia pode não ser a melhor escolha na avaliação da adiposidade central, haja visto que o volume uterino aumentado ainda em regressão tende a deslocar vísceras, causando redistribuição do tecido adiposo abdominal, podendo modificar as medidas. Um estudo conduzido em 2009 mostrou melhor correlação da quantificação da gordura visceral com medidas ultrassonográficas da gordura subcutânea (Simon et al., 2009).

\subsection{Sobre a qualidade metodológica dos artigos}

Conforme apresentado na seção de "Materiais e Métodos", os 30 artigos selecionados foram submetidos a avaliação de sua qualidade metodológica segundo um instrumento preconizado para essa análise (Downs et al., 1998). O valor para se definir uma boa adequabilidade foi de $70 \%$ da pontuação máxima do instrumento, o equivalente a pelo menos 20 pontos para os 
experimentais e 16 pontos para os observacionais (Baldoni et al., 2019).

A análise feita por dois pesquisadores de forma independente mostrou que apenas a minoria (cerca de 36\%) dos artigos apresentaram valor acima do proposto para se definir uma qualidade metodológica excelente. Dentre os pontos mais frequentemente implicados para essa limitação, destacam-se aqueles relativos à validade externa dos estudos: representatividade da amostra insatisfatória (a maioria não descreve a população máxima de onde se extraiu a amostra); descrição insuficiente sobre qual o critério de aleatorização para composição amostral; ou mesmo a não correlação entre a equipe, os lugares e as instalações nas quais os pacientes foram tratados no estudo e aqueles em que normalmente isso acontece para a população geral a que se deseja representar.

Portanto, do ponto de vista metodológico conclui-se que são necessários ainda mais estudos para avaliar com maior precisão a utilização do US na composição corporal, sobretudo com metodologias mais sólidas e robustas, para se testar de forma mais assertiva a comparabilidade do US com os demais métodos. Destaca-se a importância de se melhorar especialmente a seleção amostral dos referidos estudos, uma vez que esse foi o fator mais invariavelmente comprometido segundo a avaliação da escala de Downs. Contudo, mesmo na carência de um maior número de estudos robustos, os dados existentes apontam perspectivas promissoras do uso da ultrassonografia na determinação da composição corporal em diferentes áreas e situações clínicas.

A US mostrou-se um método com potencial aplicação prática na clínica. Embora haja boa correlação com demais métodos de avaliação da composição corporal e do potencial para aplicação em amplos campos de atuação como no acompanhamento de treinamentos físicos e dietéticos, na avaliação de patologias específicas e de alterações relacionadas ao envelhecimento, observa-se que seu uso tem sido limitado na prática diária. A carência da determinação de pontos de corte para o diagnóstico de alterações da composição corporal e de protocolos bem estabelecidos para a avaliação tanto do tecido muscular quanto do tecido adiposo, certamente dificultam muito seu uso. Contudo, alguns autores têm apontado para caminhos que podem trazer resultados mais favoráveis para a estimulação do seu uso, como utilizando equações para cálculo do percentual de gordura ou da quantificação da massa muscular, que trazem resultados mais facilmente assimiláveis para o emprego clínico. Principalmente países onde a carência de recursos financeiros diminui a oferta de equipamentos mais onerosos como a RNM ou exclusivamente utilizados para fins de determinação de composição corporal como o caso do DEXA, a disponibilidade de um método versátil que possa ser usado para diagnóstico de uma ampla gama de doenças e também para o estudo da composição corporal, traz benefícios consideráveis.

\section{Conclusão}

A avaliação de grupos musculares específicos ou de compartimentos de depósito de gordura como na quantificação da gordura intra-abdominal é uma possibilidade da US que poucos métodos usuais podem fazer com precisão. Essas qualidades associadas a não utilização de radiação ionizante fazem com que esteja entre as melhores opções no acompanhamento de treinamentos físicos ou dietéticos. A US mostra mais uma vez que dentre as suas qualidades, a versatilidade é certamente a que mais se destaca.

É importante a realização de novos e mais robustos estudos empregando a US na avaliação da composição corporal, para que seja possível o desenvolvimento e a validação de equações de determinação de massa muscular e de tecido adiposo específicas para cada população. Também é primordial que haja estudos visando o desenvolvimento protocolos de exames, viabilizando maior padronização de técnicas e regiões anatômicas de estudo. As sociedades das especialidades médicas certamente podem ter um papel estimulador nas novas pesquisas e na criação de protocolos. 


\section{Referências}

Avelar, A., Ribeiro, A. S., Nunes, J. P., Schoenfeld, B. J., Papst, R. R., Trindade, M. C. C., Bottaro, M. \& Cyrino, E. S. (2019). Effects of order of resistance training exercises on muscle hypertrophy in young adult men. Applied Physiology, Nutrition, and Metabolism. 44(4), 420-424.

Akagi, R., Takai, Y., Kato, E., Wakahara, T., Ohta, M., Kanehisa, H., Fukunaga, T. \& Kawakami, Y. (2020). Development of an equation to predict muscle volume of elbow flexors for men and women with a wide range of age. European Journal of Applied Physiology. 108, 689-694.

Akima, H., Hioki, M, Yoshiko, A., Koike, T., Sakakibara, H., Takahashi, H. \& Oshida, Y. (2016). Intramuscular adipose tissue determined by T1-weighted MRI at $3 \mathrm{~T}$ primarily reflects extramyocellular lipids. Magnetic Resonance Imaging. 34(4), 397-403.

Baldoni, N. R., Aquino, J. A., Alves, G. A. S., Sartorelli, D. S. S., Franco, L. J., Madeira, S. P. \& Fabbro, A. L. D. (2019). Prevalence of overweight and obesity in the adult indigenous population in Brazil: A systematic review with meta-analysis. Diabetes \& Metabolic Syndrome. 13(3), 1705-1715.

Bazzocchi, A., Diano, D., Ponti, F., Salizzoni, E., Albisinni, U., Marchesini, G. \& Battista, G. (2014). A 360-degree overview os body composition in healthy people: Relationships between anthropometry, ultrasonography, and dual-energy x-ray absorptiometry. Nutrition. 30, 696-701.

Belavý, D. L., Armbrecht, G. \& Felsenberg, D. (2015). Real-time ultrasound measures of lumbar erector spinae and multifidus: reliability and comparison to magnetic resonance imaging. Physiological Measurement. 36, 2285-2299.

Belem, L. H. J., Nogueira, A. C. S., Schettino, C. D., Barros, M. V. L., Ancantara, M. L., Studart, P. C. C., Araújo, P. P., Amaral, S. I., Barretto, S. \& Guimarães, J. I. (2004). Normatização dos equipamentos e das técnicas para a realização de exames de ultrassonografia vascular. Arquivos Brasileiros de Cardiologia. 82(6), $1-14$.

Berger, J., Bunout, D., Barrera, G., Pía, M. M., Henriquez, S., Leiva, L. \& Hirsch, S. (2015). Rectus femoris (RF) ultrasound for the assessment of muscle mass in older people. Archives of Gerontology and Geriatrics. 61(1), 33-8.

Berker, D., Koparal, S., Işık, S., Paşaoğlu, L., Aydın, Y., Erol, K., Delibaşı, T. \& Güler, S. (2010). Compatibility of different methods for the measurement of visceral fat in different body mass index strata. Diagnostic and Interventional Radiology. 16, 99-105.

Carbone, F., Migliola, E. N., Bonaventura, A., Vecchié, A., Vuono, S., Ricci, M. A.,Vaudo, G., Boni, M., Dallegri, F., Montecucco, F. \& Lupattelli, G. (2015). High serum levels of C-reactive protein (CRP) predict beneficial decrease of visceral fat in obese females after sleeve gastrectomy. Nutrition, Metabolism \& Cardiovascular Diseases. 28(5), 494-500.

Ceniccola, G. D., Castro, M. G., Piovacari, S. M. F., Horie, L. M., Correa, F. G., Barrere, A. P. N. \& Toledo, D. O. (2018). Current technologies in body composition assessment: advantages and disadvantages. Nutrition. 62, 25-31.

Downs, S. H. \& Black, N. (1998). The feasibility of creating a checklist for the assessment of the methodological quality both of randomised and non-randomised studies of health care interventions. Journal of Epidemiology and Community Health. 52(6), 377-84

Fortin, M., Rizk, A., Frenette, S., Boily, M. \& Rivaz, H. (2019). Ultrasonography of multifidus muscle morphology and function in ice hockey players with and without low back pain. Physical Therapy in Sport. 37, 77-85.

Fosbol, M. O. \& Zerahn, B. (2014). Contemporary methods of body composition measurement. Clinical Physiology and Functional Imaging. 35(2), 81-97.

Hiokia, M., Kanehirab, N., Koikec, T., Saitod, A., Shimaokaf, K., Sakakibaraa, H., Oshidac, Y. \& Akimac, Y. (2020). Age-related changes in muscle volume and intramuscular fat content in quadriceps femoris and hamstrings. Experimental Gerontology. 132, 110834.

Heckmatt, J. Z. \& Dubowitz V. (1984). Diagnosis of spinal muscular atrophy with pulse echo ultrasound imaging. In: Gamstorp, I. \& Samat, H. B. Progressive spinal muscular atrophies. 141-51.

Ismail, C., Zabal, J., Hernandez, H.J., Woletz, P., Manning, H., Teixeira, C., DiPietro, L., Blackman, M. R. \& Love, M. O. H. (2015). Diagnostic ultrasound estimates of muscle mass and muscle quality discriminate between women with and without sarcopenia. Frontiers in Physiology. 6 , 302.

Joy, J. M., Falcone, P. H., Vogel, R. M., Mosman, M. M., Kim, M. P. \& Moon, J. R. (2015). Supplementation with a proprietary blend of ancient peat and apple extract may improve body composition without affecting hematology in resistance-trained men. Applied Physiology, Nutrition, and Metabolism. 40(11), 11717 .

Leahy, S., Toomey, C., McCreesh, K., O’Neill, C. \& Jakeman, P. (2012). Ultrasound measurement of subcutaneous adipose tissue thickness accurately predicts total and segmental body fat of young adults. Ultrasound in Medicine and Biology. 38 (1), 28-34.

Melvin, M. N; Ryan, A. E. S; Wingfield, H. L., Ryan, E. D., Trexler, E. T. \& Roelofs, E. J. (2014). Muscle characteristics and Body Composition of NCAA Division I Football Players. Journal of Strength and Conditioning Research. 28(12), 3320-3329.

Midorikawa, T., Ohta, M., Hikihara, Y., Torii, S. \& Sakamoto, S. (2015). Prediction and validation of total and regional skeletal muscle volume using B-mode ultrasonography in Japanese prepubertal children. British Journal of Nutrition. 114(8), 1209-17.

Midorikawa, T., Ohta, M., Hikihara, Y., Torii, S., Bemben, M. G. \& Sakamoto, S. (2011). Prediction and validation of total and regional fat mass by B-mode ultrasound in Japanese pre-pubertal children. British Journal of Nutrition. 106(6), 944-50.

Nijholt, W., Wittenaar, H. J., Raj, I. S., Schans, C. P. \& Hobbelen, H. (2019). Reliability and validity of ultrasound to estimate muscles: A comparison between different transducers and parameters. Clinical Nutrition ESPEN. 35, 146-152.

Novais, R. L. R., Café, A. C. C., Morais, A. A., Bila, W. C., Santos, G. D. S., Lopes, C. A. O., Belo, V. S., Romano, M. C. C. \& Lamounier, J. A. (2018). Intraabdominal fat measurement by ultrasonography: association with anthropometry and metabolic syndrome in adolescents. Jornal de Pediatria. 95(3), 342-349. 
O’Neill, D. C., Cronin, O., O’Neill, S. B., Woods, T., Keohane, D. M., Molloy, M. G. \& Falvey, E. C. (2015). Application of a Sub-set of Skinfold Sites for Ultrasound Measurement of Subcutaneous Adiposity and Percentage Body Fat Estimation in Athletes. International Journal of Sports Medicine. 37(5), 359-63.

Page, M. J., McKenzie, J. E., Bossuyt, P. M., Boutron, I., Hoffmann, T. C., Mulrow, C. D., Shamseer, L., Tetzlaff, J. M., Akl, E. A., Brennan, S. E., Chou, R. et al. (2021). The PRISMA 2020 statement: an updated guideline for reporting systematic reviews. The British Medical Journal. 10(1), 89.

Paris, M. T. \& Mourtzakis, M. (2018). Development of a bedside-applicable ultrasound protocol to estimate fat mass index derived from whole body dual-energy X-ray absorptiometry scans. Nutrition. 57, 225-230.

Paris, M. T., Mourtzakis, M., Day, A., Leung, R., Watharkar, S., Kozar, R., Earthman, C., Kuchnia, A., Dhaliwal, R., Moisey, L., Compher, C., Martin, N., Nicolo, M., White, T., Roosevelt, H., Peterson, S. \& Heyland, D. K. (2016). Validation of Bedside Ultrasound of Muscle Layer Thickness of the Quadriceps in the Critically Ill Patien (VALIDUM Study): A Prospective Multicenter Study. Journal of Parenteral and Enteral Nutrition (JPEN). 41(2), 171-180.

Pettersson, C. W., Kivisaari, L., Jaaskelainen, J., Lamminen, A. \& Holmberg, C. (1989). Ultrasonography, CT, and MRI of Muscles in Congenital Nemaline Myopathy. Pediatric Neurology. 6(1), 20-8.

Reidy, P. T., Borack, M. S., Markofski, M. M., Dickinson, J. M., Deer, R. R., Husaini, S. H., Walker, D. K., Ibinigie, S., Robertson, S. M., Cope, M. B., Mukherjea, R., Porter, J. M. H., Jennings, K., Volpi, e. \& Rasmussen, B. B. (2016). Protein Supplementation Has Minimal Effects on Muscle Adaptations during Resistance Exercise Training in Young Men: A Double-Blind Randomized Clinical Trial. The Journal of Nutrition. 146(9), 1660-9.

Roelofs, E. J., Ryan, A. E. S., Melvin, M. N; Wingfield, H. L., Trexler, E. T. \& Walker, N. (2015). Muscle size, quality, and body composition: Characteristics of division I cross-country Runners. Journal of Strength and Conditioning Research. 29(2), 290-296.

Roelofs, E. J., Ryan, A. E. S., Trexler, E. T. \& Hirsch, K. R. (2016). Seasonal Effects on Body Composition, Muscle Characteristics, and Performance of Collegiate Swimmers and Divers. Journal of Athletic Training. 52(1), 45-50.

Rolfe, E. L., Norris, S. A., Sleigh, A., Brage, S., Dunger, D. B., Stolk, R. P. \& Ong, K. K. (2011). Validation of Ultrasound Estimates of Visceral Fat in Black South African Adolescents. Obesity (Silver Spring). 19(9), 1892-7.

Rowe, G. S., Blazevich A. J. \& Haff, G. G. (2019). pQCT- and Ultrasound-based Muscle and Fat Estimate Errors after Resistance Exercise. Medicine \& Science in Sports \& Exercise. 51(5), 1022-1031.

Sanada, K., Kearns C. F, Midorikawa, T. \& Abe, T. (2006). Prediction and validation of total and regional skeletal muscle mass by ultrasound in Japanese adults. European Journal of Applied Physiology. 96 (1), 24-31.

Schlecht, I., Wiggermannb, P., Behrens, G., Fischer, B., Kochc, M., Freese, J., Rubine, D., Nöthlings, U., Stroszczynski, C., Leitzmanna, M. F. (2014). Reproducibility and validity of ultrasound for the measurement of visceral and subcutaneous adipose tissues. Metabolism. 63(12), 1512-9.

Schryver, A., Rivaz, H., Rizk, A., Frenette, S., Boily, M. \& Fortin, M. (2020). Ultrasonography of Lumbar Multifidus Muscle in University American Football Players. Medicine \& Science in Sports \& Exercise. 52(7), 1495-1501.

Simon, C. S., Thureen, P., Stamm, E. \& Scherzinger, A. (2009). A comparison of four techniques for measuring central adiposity in postpartum adolescents. Journal of Maternal-Fetal Medicine. 10(3), 209-213.

Stolk, R. P., Wink, O., Zelissen, P. M., Meijer, R., Gils, A. P. \& Grobbee, D. E. (2001). Validity and reproducibility of ultrasonography for the measurement of intra-abdominal adipose tissue. International Journal of Obesity. 25, 1346-51.

Thoirs, K. \& English, C. (2009). Ultrasound measures of muscle thickness: intra-examiner reliability and influence of body position. Clinical Physiology and Functional Imaging. 29(6), 440-6.

Thomaes, T., Thomis, M., Onkelinx, S., Coudyzer, W., Cornelissen, V. \& Vanhees, L. (2012). Reliability and validity of the ultrasound technique to measure the rectus femoris muscle diameter in older CAD-patients. BMC Medical Imaging. 12 (1), 7.

Tillquist, M., Kutsogiannis, D. J., Wischmeyer, P. E., Kummerlen, C., Leung, R., Stollery, D., Karvellas, C. J., Preiser, J. C., Bird, N., Kozar, R. \& Heyland, D. K. (2014). Bedside ultrasound is a practical and reliable measurement tool for assessing quadriceps muscle layer thickness. Journal of Parenteral and Enteral Nutrition. 38(7), 886-90.

Trexler, E. T., Ryan, A. E. S., Roelofs, E. J. \& Hirsch, K. R. (2015). Body Composition, Muscle Quality and Scoliosis in Female Collegiate Gymnasts: A Pilot Study. International Journal of Sports Medicine. 36, 1087-1092.

Wang, Z. M., Pierson Jr, R. N. \& Heymsfield, S. B. (1992). The five-level model: a new approach to organizing body composition research. The American Journal of Clinical Nutrition, 56, 19-28.

Weisgarber, K. D., Candow, D. G. \& Vogt, E. S. M. (2012). Whey protein before and during resistance exercise has no effect on muscle mass and strength in untrained young adults. International Journal of Sport Nutrition and Exercise Metabolism. 22, 463-469. 